\title{
Developing Reading Skills in Children with Down Syndrome through Tangible Interfaces
}

\author{
Bárbara Paola Muro Haro \\ IHCLab \\ School of Telematics \\ University of Colima \\ pao_muro@ucol.mx
}

\author{
Pedro C. Santana \\ IHCLab \\ School of Telematics \\ University of Colima \\ psantana@ucol.mx
}

\author{
Martha A. Magaña \\ School of Pedagogy \\ University of Colima \\ mc2103@ucol.mx
}

\begin{abstract}
This paper describes the results of an experimental study implementing a teaching technological strategy to help Down syndrome children develop their reading skills. The study employed the pedagogical method proposed in "Down syndrome: reading and writing" (DSRW) book, augmented with tangible interfaces, showing favorable results when tested on kids with this syndrome.
\end{abstract}

This study was developed in three stages:

First, a direct observation was conducted to help us understand the context of applying the DSRW methodology in sessions with Down children without any technological strategy involved. Using the results of the observations, a multi-touch interactive concept design was created which integrates tangible elements and software applications maintaining a pedagogical precision.

The second stage included the evaluation of the first prototype of the design, created to test the reaction of a child with Down syndrome when a child is exposed to the tangible technology.

Finally, the third stage consisted in the evaluation of a second, and more elaborated prototype that is more similar to the conceptual design.

\section{Categories and Subject Descriptors}

H.5.2 [Information Interfaces and Presentation]: User Interfaces - user-centered design, evaluation/methodology, input devices and strategies.

\section{General Terms}

Human Factors.

\section{Keywords}

Down syndrome, tangible interfaces, inclusive design.

\section{INTRODUCTION}

Statistically, in Mexico, 1 of every 700 births is a child with Down syndrome [1].

By 2010, in Mexico there were 5'739,270 handicapped people of which $8.5 \%$ are mentally disabled and 16.3 percent are born with

\footnotetext{
Permission to make digital or hard copies of part or all of this work for personal or classroom use is granted without fee provided that copies are not made or distributed for profit or commercial advantage and that copies bear this notice and the full citation on the first page. Copyrights for components of this work owned by others than ACM must be honored. Abstracting with credit is permitted. To copy otherwise, to republish, to post on servers or to redistribute to lists, requires prior specific permission and/or a fee.

MexIHC '12, October 03 - 05 2012, Mexico city, Mexico

Copyright 2012 ACM 978-1-4503-1659-0/12/10 ...\$15.00
}

a disability [2].

30 years ago, most people with Down syndrome could not read. The reason is that it was considered that they had no ability to do so, and in case of having it, it was thought that it would be useless. In short, they were deprived of learning to read [3].

Nowadays, there are several methods for teaching reading and writing to children with Down syndrome, for example "Down syndrome: reading and writing" (DSRW). DSRW is a book that explains a method developed in 1970. It was published in 1991 and it uses a perceptual-discriminative approach to teach these children to read before they are 5 years old. The priority and fundamental purposes in this method is that the student understands what he reads, fluently, to remain motivated and to keep his interest in reading [4].

One of the conditions of Down syndrome is the deficit of attention. Even though they present this problem, the student will pay attention to the activity if it is of his interest. It is hard for him to concentrate when only oral information is being presented to him, it is therefore appropriate to incorporate other kind of stimulations [5].

In this sense, it was thought of an interesting, stimulating and fun way to expose these children to this learning methodology..

Tangible interfaces have been proved to offer certain benefits in supporting education [6], and had been tested on children with autism (condition that also presents attention deficit) showing favorable results [7].

This paper will present the favorable results produced when adapting the DSRW methodology in an interactive technology using tangible interfaces when tested on kids with Down syndrome.

\section{PREVIOUS WORK}

Technology supports us in all areas of human life, including education and recently, special education.

Human - Computer Interaction (HCI) is the study of the interaction between humans, computers and the developed tasks; it is focused mainly in knowing how people and computers can interact to perform tasks through systems and software [8]. Nowadays, HCI is very important in the creation of technologies focused in being used by people and this importance becomes relevant when working with disabled people.

An investigation about existent work that combines technology and HCI, for people with Down syndrome is presented below. 


\subsection{Methodologies for teaching writing and reading to people with Down syndrome}

\subsubsection{LATCH-ON.}

Latch-on is a program of the University of Queensland, Australia. It was developed and put into practice in 1998 [9], especially for young adults with Down syndrome who have had education through their lives. It proposes to impulse the habit of reading using several university libraries, museums and technology (computers). This program lasts two years.

\subsubsection{Down syndrome: Reading and writing.}

A methodology created by María Victoria Troncoso y María Mercedes del Cerro. This methodology is based in the learning pedagogy of perceptual-discriminative learning. The method is posed in a book/manual [10] which explains from the foundations, theory and data about Down syndrome, its pathology and ways of learning; the correct usage of the method and it also includes the material for its implementation.

\subsubsection{See and Learn Language and Reading [11].}

This is a program of activities designed for visually strong learners such as Down syndrome children meant to be. It consists of 3 stages and 5 steps. Stage 1: Learners are taught 60 common words without going through the reading comprehension process, and learn the name-object relation. Stage 2: The learners are taught 16 written words and learn how to join words. Stage 3: Learners are able to assemble simple sentences with the more of 70 words that they already have in their vocabulary, teaching certain key words to join sentences

\subsection{Technology for the education of people with Down syndrome}

\subsubsection{Sound beginnings 2.}

This software allows the selection of proper sounds, phonemes and words, it also allows to upload and use own images [12]. It can be configured to fit specific requirements, like:

- Gradual revealing of images through sound stimulation.

- $\quad$ Praising the student for saying specific words.

With Sound beginnings 2 one can also register the individual progress through printable "user records".

\subsubsection{Clicker.}

It is a software designed to teach reading and writing by using images and sounds, creating relations, putting sentences together, etc. [13]. It develops hearing abilities, encourages practice to speaking skills with "talking books" created by the professor and it focuses on the form of the language using sentence which is separated in its different components (subject, verb and complement), in which every component is inside a box of a different color.

\subsubsection{My first number game.}

This is an application developed for the iPod touch and iPad, which makes it a touch application [14]. It is an application that was not designed for people with Down syndrome, but the Down Syndrome Association of Queensland (DSAQ) has acknowledged it as a useful teaching resource for this condition. My first number game is totally customizable; it teaches numbers from 1 to 20 . One can create new categories and add new cards using images and voice recordings.

\subsection{Technology for the learning of reading and writing for children with Down syndrome}

\subsubsection{I like to read.}

Global reading methodology with computer support [15]. This is software developed by the Down Syndrome Association of Granada (GRANADOWN). Its main characteristics are: it uses a global methodology, individualized, success oriented, applied in a playful and motivating way and using visual material.

This investigation shows that there are very few technologies applied to the teaching of reading and writing to people with Down syndrome. It is also noticeable that most of the teaching methods are based on the perceptual-discriminative pedagogy, but each one has its own limitations.

\section{THE METHOD, DOWN SYNDROME: READING AND WRITING}

DSRW is a book that explains a method developed in 1970 and published in 1991 that uses a perceptual-discriminative approach to teach children with Down syndrome to read before they are 5 years old.

DSRW uses educational material with specific colors, sizes and fonts that will facilitate the learning process; this material is customizable and adaptable, for it to fit each student's needs and learning level. All of the material, information and instructions on how to apply the method are published in a book that is now available for everyone through the Internet ${ }^{1}$.

Prior using this method, it is recommendable that the kid had already participated in a perceptual-discriminative learning program. It is not a problem if the child has not started to talk, but it is a mandatory that he knows that people, animals, things and actions have names.

For example; when the child hears the word "ball", he knows what object we refer to, and, even though he does not pronounce it, he locates and evokes it. Likewise, when the word "ball" is presented, the child remembers and evokes it, understanding that the written visual information corresponds to the object known by him as "ball".

The advantages of presenting a graphic written word on a piece of paper (which is always accompanied by oral information) to the learner versus oral presentation, are two: on the one hand, there is double stimulus because it goes through the visual and auditory pathway; and, the written word stays in sight the whole time, which makes it easier to fix it in memory [16].

\section{APPLICATION OF THE METHOD}

An example of the use of the method will be explained.

\subsection{Material}

Image card. It contains an image and underneath the written word that represents it (Figure 1a).

Word card. This card has written on it the same word that is represented in the image card (Figure 1b).

${ }^{1}$ http://www.down21 materialdidactico.org/librolectura/index.html 


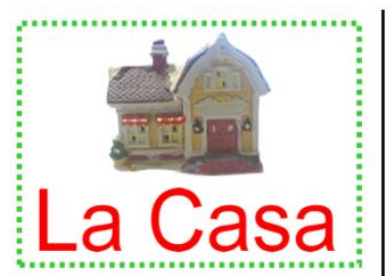

(a)
La Casa

(b)
Figure 1. Image-cad and Word-card.

\subsection{Exercise}

The adult -teacher, familiar- reads the word in the image card repeatedly pointing at it with his finger. Later, he asks the child to read the word in the card.

The adult shows the child the word card and points the fact that both cards (image card and word card) have the same word written on them and then asks him to read what the cards say. After that, the adult indicates to the child to put one word on top of the other saying "put la casa over la casa".

The purpose of this exercise is that the learner relates the written words with its correspondent image and the sound of reading it and, in the future, the learner would be able to recognize the word without the image.

\section{TANGIBLE INTERFACES}

Tangible interfaces give physical form to digital information, employing physical objects both as representations and controls for computational media. Tangible user interfaces (TUIs) match physical representations (e.g., spatially easy to use physical objects) with digital representations (e.g., graphics and audio), yielding user interfaces that are computationally mediated but generally not recognizable as "computers" per se [17].

It has been proven that using tangible interfaces offers some benefits in supporting teaching [6], they have been tested on children with autism, which is a condition with attention deficit that is also found in the DS, demonstrating favorable results [7]. Studies alike [18] show that are useful because they promote an active participation, which helps with the learning process. These interfaces do not intimidate non-expert users and encourage exploratory, expressive and experimental activities.

\section{UNDERSTANDING THE DSRW}

The followed methodology is based on the User Centered Design approach, which helped us to understand the context of applying the DSRW methodology in the sessions with children without any technological strategy involved.

The used technique for this case of study was direct observation. Direct observation is when the investigator is placed in personal contact with the fact or phenomenon under investigation.

The observations were performed at the Down Institute of Colima. Three sessions with children of different ages and at different levels of the method were observed and recorded in video for later analysis.

The book of DSRW [10] mentions three stages of the reading learning process:

- First stage: Global perception and recognition of written words.
- Second stage: Recognition and learning of syllables.

- Third stage: Progress in reading.

Our sample was: Ricardo, a kid of $3^{\circ}$ level $^{2}$ that is in stage 1 of learning; Alex, a teenager of $4^{\circ}$ level in stage 3 and Fernando, a young adult in stage 2 .

After observing these sessions and analyzing the videos, we got the following findings:

\subsection{Ricardo}

The main problem with Ricardo was his lack of attention and interest after a few minutes of work. He is distracted by any sound, loses interest and starts to yawn.

The technique that the teacher uses to get back his attention is to ask him to do some exercises with his hands, like touching his nose and in other moments, she "threatens" him with sending him to his classroom and ending the session.

\subsection{Fernando}

Fernando yawns a lot from the beginning of the session. He pays more attention to the activities but shows certain resistance to do them.

When the teacher asks for his help to do something, Fernando answers that he does not want to help her, so the teacher acts like if the answer hurts her feelings and then Fernando agrees to do the activities.

The teacher uses the technique of giving him activities where he has to draw something, because she knows that drawing is an activity that Fernando enjoys a lot.

\subsection{Alex}

With Alex we observed a smoother session, his attention is rarely away from the activities and it is noticeable that he gives a little more thought to his answers.

In contrast with the other two students, he only yawned once in the entire session. Also, when he answers correctly and the teacher congratulates him, he smiles and shows a little more motivation.

After analyzing the observations, the following was concluded:

As a professor applying the method, it is important to know your students, to know how to get their attention and engage them into the activities. Also, it is necessary to learn not to show negative reactions when the student makes a mistake and to praise him when he does things right.

Regarding the students, most of them show a lack of interest in the activities and it is notable in their lack of attention. This could be because of the deficit of attention presented in their condition or maybe because the sessions took place early in the morning.

We notice that is necessary to motivate learners with interactive activities, because when they are only repeating words (which is an important part of the method) it is when they show the most lack of interest and boredom.

\footnotetext{
2 The Down Institute of Colima separates the students in levels according to their ages. (E.g., kids from 3 to 6 years are level 1).
} 


\section{THE SYSTEM}

Using the results previously mentioned as a starting point, tangible interfaces will be used in this investigation [19] with the purpose of proving its feasibility.

The design proposed here, is a multi-touch interactive concept that integrates tangible elements and software applications maintaining pedagogical precision.

The idea for the user interface is a tabletop and a set of digitally augmented tools that would include the educational material used in DSRW (word card and image card) and they will be tagged with augmented reality tags so they can be recognized by the software.

\subsection{Design and architecture}

As it was mentioned before, our system proposal is the combination of a tabletop, tangible interfaces and software (see Figure 2).

The tabletop consists of a table with a clear surface, almost transparent, where the cards of the educational material will be projected and at the same time, it allows the Reading of the augmented real tags by a web camera.

The tangible interfaces will be physical objects representative of the images or words that are presented to the students. These objects have underneath augmented real tags which are read by a web camera placed under the table.

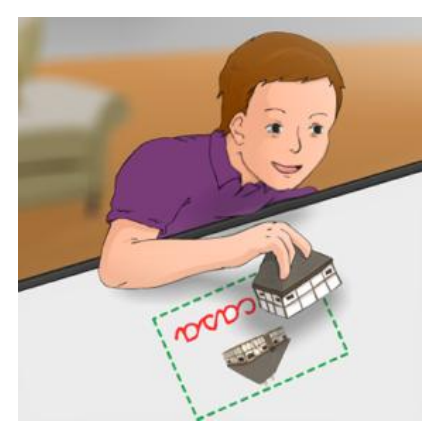

Figure 2. Storyboard of the tangible system

The camera sends the reading to the software specially created for our prototype. This prototype processes it and recognizes if the tag of the toy corresponds to the word card or image card projected on the table, and based on this, it provides feedback to the user.

The software has the characteristics for allowing the adult (teacher, familiar) to create and customize the cards, save certain cards and the sequence that he designs for a specific session with the kid and also store data from the sessions, like the number of right and wrong answers.

Our system also allows the user to move between the cards and activities with gestures like a flick or a tap.

For the system to work, a multi-layer architecture was proposed and described in Figure 3.

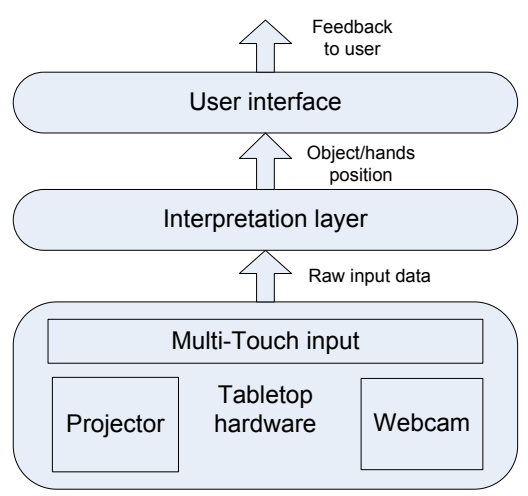

Figure 3. System architecture

The lower layer is the hardware, which generates monitoring raw data in the format of a video sequence, doing this by using a projector and a webcam.

Them, the information is interpreted by the layer that translates the gestures on the surface and recognizes the augmented reality tags.

Finally, the user interface layer generates the visible feedback for the user. It receives the events of the interpretation layer.

\section{USAGE SCENARIO}

To illustrate the functionality of the system, we present the following scenario of use that describes how a child would interact with the tabletop and the tangible interfaces:

Ricardo is a kid with Down syndrome. He goes to a special school because of his learning needs. Ricardo's school uses the system. Twice a week, Ricardo has personal sessions with his teacher where she teaches him to read and write using the tabletop. Ricardo is just starting with the method, so his teacher is teaching him to relate words with images and sounds.

Today, Ricardo's teacher asks him to do an exercise where he has to relate a word with its image, on the tabletop a word card is projected and he has three tangible objects in front of him, he has to choose an object that represents the word that he is seeing projected on the tabletop. Once Ricardo has made his election, he places the object on the corresponding area and the system indicates him whether he is right or wrong.

\section{PRELIMINARY EVALUATION}

A first prototype was created to test the reaction of a child with Down syndrome when a tangible technology is presented to him, the way he might interact with it and see if it generates any interest in the child.

This prototype was made using a tablet to simulate the touch surface. The tablet was in the middle of a wooden frame to represent the table.

Some toys were chosen to be the tangible interfaces: a house, a car, a bed and a chair (see Figure 4).

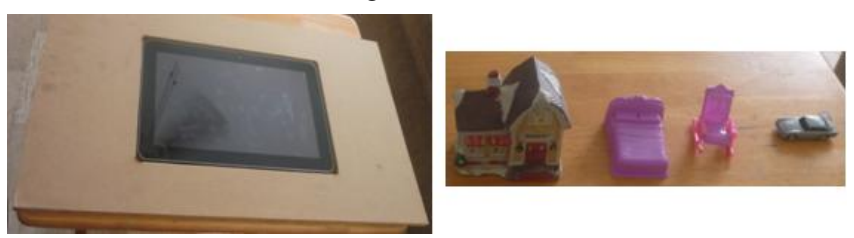

Figure 4. First prototype 
To simulate the functionality of the system in the tablet, we saved in it the educational material (word card and image card) as a PDF document.

\subsection{Testing the first prototype}

The potential advantages of tangible interfaces cannot be perceived until they are situated in an interaction context. Preliminary evaluations are an ideal mechanism to go beyond current practices and allow us to get involved in the design process and visualize new schemes of application in a simple and economic way [20].

To explore the feasibility of the conceptual design, a preliminary evaluation was conducted, testing the scenario of use and the prototype with a kid with Down syndrome, his parents and a teacher (see Figure 5). These evaluations were video recorded and photographed.

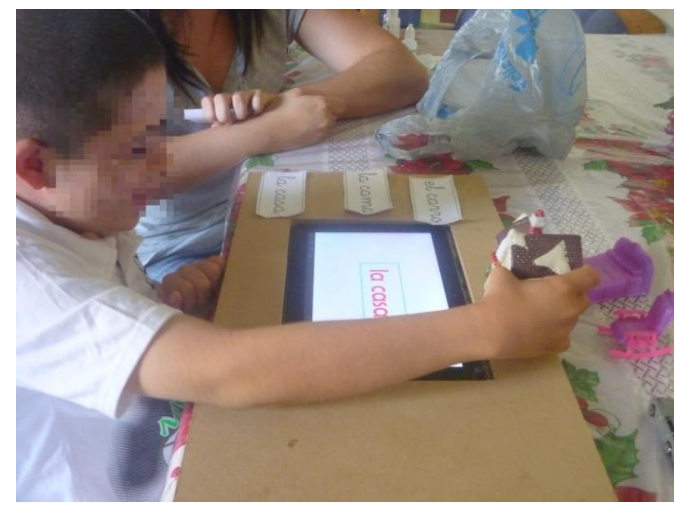

Figure 5. Preliminary evaluation

The evaluation took place in the learner's house. It included two main phases. First, the parents were informed about the process and the method was discussed. Later, we showed the prototype to the student pointing its functionalities and we explained to him the activities to be carried out in the session.

Before initiating the test, we presented to the student the words that were used in the evaluation and performed a few warm up exercises so he would remember the method. Finally, the scenario of use was applied.

\subsection{Results}

After analyzing the videos and the observations of the evaluators, the following was concluded:

During the preliminary evaluation, the student with Down syndrome found interesting and exciting the fact that the system improves the interaction that he generally has with the method.

It was noticeable during the whole session a constant attention and a permanent expression of joy and interest. An important result was that the child maintained his attention in the activities all the time, without the need of instructions or additional encouragement for him to continue working.

By the end of the session, the child did not want to stop interacting with the prototype and he, by his own initiative, continued working with it.

\section{THE SECOND PROTOTYPE}

After the first evaluation, we noticed that in order to have a better context of the interaction with the system and observe the reactions of the learners, we needed to create a more elaborated prototype that is more similar to the conceptual design.

The tabletop was built (see Figure 6), the interaction software was created and we used the same toys used in the previous evaluation as the tangible objects. In addition, we created physical word cards to be used as tangible interfaces in order to perform a complete cycle of exercises (relation word-image).

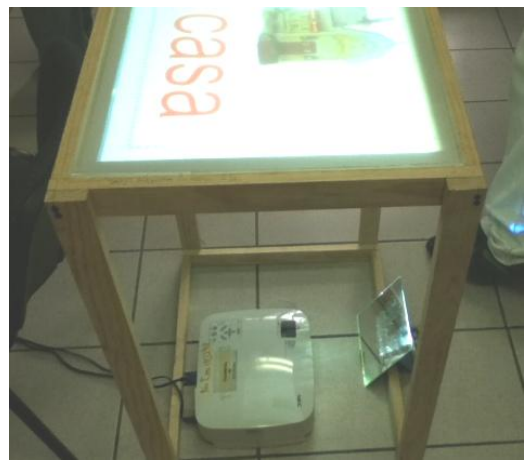

Figure 6. Prototype tabletop

The prototype consisted of a table with clear surface that underneath had a projector and a mirror so the images would project on the tabletop. The projector was connected to a computer running the sample software.

\subsection{Evaluation}

The test took place in the Down Institute of Colima facilities with three children, the same three who were object of the direct observation conducted at the beginning of this investigation.

For this evaluation, one evaluator, three observers and the two teachers in charge of the application of the DSRW method in the school attended the sessions.

The sessions were video recorded and the observers took photographs and notes. The evaluation was carried out following a protocol of evaluation that described each step along the whole test, as follows:

First, we applied a structured interview to the teacher asking her experience in special education, and more specifically, with the method. Then, we explained to her the concept of the system, the design and the functionality of the prototype. Finally we asked some questions about the opinion that the teacher could create about the system from the given explanation.

After the introduction with the teacher, the evaluation with the students started. The sessions with the students took no more than 20 minutes. All the sessions started with the evaluation team introducing themselves and giving a brief introduction of the reasons of why the student was there and what was wanted from him.

Following the introduction, the evaluation started with a warm up exercise as a reminder of the method where the student read four image-cards projected on the tabletop.

The words used in all the educational material for this evaluation were: the house (la casa), the car (el carro), the bed (la cama) and the chair (la silla).

After the warm up exercise, each student performed 3 activities:

- Reading of 4 word cards projected on the tabletop. 
- Relation of the tangible interfaces (toys) with the projected word cards on the tabletop.

- Relation of the tangible interfaces (word card) with the projected image cards on the tabletop.

At the end of the three evaluations with the learners (see Figure 7), a final interview was made to the teacher asking her observations in the sessions about the reaction of the children, differences between the activities carried out in a traditional way and the ones using the system, and also their general opinions.

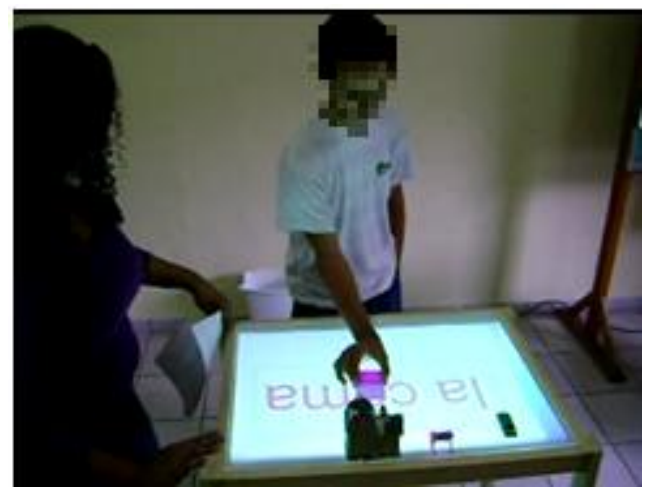

Figure 7. Second evaluation

\subsection{Results}

Thanks to the analysis of the videos, the notes and the observations from the evaluator, the observers and the teachers, the following results were obtained:

During the sessions, the students showed interest and curiosity when interacting with the prototype. They were anxious to handle the tangible interfaces and place them where they were asked to. One of the students, a shy one, made the "thumb up" signal to his teacher when he thought the evaluator was not watching.

The opinions of the teachers were very positive, mentioning "I observed that they (the learners) were fascinated" and said that maybe the learners would learn faster with the interaction that the system allows them to have and that having this kind of technology would make them feel more integrated to society because then they would also know how to use technology.

One of the teachers made a comparison with software that the kids use in computers at school called "activities with Pipo", saying that with the computer the learners need to interact with the mouse and it is not very easy for them, and if they do not have a monitor they get bored because of this. With the prototype, the fact that the material is tangible and easily manageable, it complements the activities and makes the interaction much easier.

The general opinion of the first teacher was "wow!" and she would really like to use the system once it is finished. The second teacher commented that she was very interested in learning how to implement the system in regular classes.

\section{CONCLUSION}

This work proposes to improve the process of the learning of reading and writing of children with Down syndrome through the usage of tangible interfaces. An interactive system was designed that presented favorable results in preliminary evaluations, taking into account that the measures were the interest of the user with
Down syndrome towards the system and the focused attention to the activities.

In the second evaluation, the results were very pleasant, because it was used a more faithful prototype to the concept design, also measuring the acceptance of the users with Down syndrome. The users showed enthusiasm, curiosity, excitement and desire to participate in the activities.

In addition to this, the system obtained good reviews from the teachers that attended the evaluation sessions. They also showed enthusiasm towards the system, wanting to learn how to use it and asking for it to be presented to the institution once it is finished.

With the implementation of this system we pretend to generate a positive impact on the kids with Down syndrome and, eventually, support the DSRW method to perform better through the use of technology.

Our further work consists of the enhancement of the prototype to have even closer to the desired final design and test it in long terms. In this third evaluation we want to measure the progress through several months and comparing it to the teaching of the method in a traditional way. The final objective is to see if the learning process with our system is faster and better than the traditional methodology.

\section{ACKNOWLEDGMENTS}

We thank the Down Institute of Colima for their collaboration and facilitations for us to do our study and tests.

Thanks to the students Sergio Zamora, Hector Quintero, Eneida Sánchez and Nashielly Merlín of the IHCLab Research Group at the University of Colima for their help in the realization of the tests and building the second prototype.

\section{REFERENCES}

[1] Cruz Martínez, Á. México, rezagado en socialización de personas con síndrome de Down. La Jornada. 25 de Abril de 2008.

[2] INEGI. Discapacidad en México. http://cuentame.inegi.org.mx (2010).

[3] Down 21. Lectura y escritura. http://www.down21.org/web_n/index.php?option=com_cont ent \&view $=$ article $\& i d=1136:$ lectura- $y$ escritura\&catid=92: educacion\&Itemid=2084 (2000).

[4] Troncoso, M. V. Características de los alumnos con síndrome de Down.

http://www.down21.org/web_n/index.php?option=com_cont ent $\&$ view $=$ article $\& i d=1136 \% 3$ Alectura- $y$ -

escritura\&catid $=92 \% 3$ Aeducacion\&Itemid $=2084 \&$ limitstart $=3(2000)$.

[5] Troncoso, M. V., Del Cerro, M. Características del método. http://www.down21.org/web_n/index.php?option $=$ com_cont ent $\&$ view $=$ article $\& i d=1136 \% 3$ Alectura- $y$ escritura\&catid $=92 \% 3$ Aeducacion\&Itemid $=2084 \&$ limitstart $=3$ (2001).

[6] Marshall, Paul. Do tangible interfaces enhance learning?. In TEI'07 (2007).

[7] Keay-Bright, Wendy. Tangible Technologies as Interactive Play Spaces for Children with Learning Difficulties: The Reactive Colours Project. The International Journal of Technology, Knowledge and Society (2008). 
[8] Martínez de la Teja, G. M. Ergonomía e interfaces de Interacción Humano - Computadora. IX Congreso Internacional de la Ergonomía, México, D.F. (2007), 8.

[9] Moni, Karen B. y Jobling, Anee. LATCH-ON: A program to develop literacy in young adults with Down syndrome. Academic Research Library (2004), 44.

[10] Troncoso, M. V., \& Del Cerro, M. M. Síndrome de Down: Lectura y escritura. Fundación Iberoamericana Down 21 (2009).

[11] International Down syndrome Education. See and Learn. http://www.seeandlearn.org/en/gb/language-reading/ (2011).

[12] Black, Bob. Educational software for children with Down Syndrome -an update. Down Syndrome News and Update Vol. 6 (2006).

[13] Ltd., Crick Software. Clicker \& Special Needs - Speach or Language Impairments. Clicker web site (2011).

[14] Inc., Down Syndrome Association of Qld. Technology for children and adults with Down Syndrome. http://dsaq.probitypartners.com.au/down-syndromeinformation/technology (2011).
[15] Álvarez Martínez, S,, López-Moratalla López, I. Me gusta leer: método de lectura global con soporte informático. Granada: Proyecto Sur Industrias Gráficas, S.L. (2008).

[16] Troncoso, M. V., Díaz-Caneja, P. Perspectiva histórica. http://www.down21.org/web_n/index.php?option=com_cont ent \&view $=$ article \&id $=1136 \% 3$ Alectura- $y$ -

escritura \&catid $=92 \% 3$ Aeducacion \&Itemid $=2084 \&$ limitstart $=2(2000)$.

[17] Ullmer, B., Ishii, H. Emerging frameworks for tangible user interfaces. IBM Systems Journal , 39 (2000), 3-4.

[18] Carreras, A., Parés, N. Diseño de una instalación interactiva destinada a enseñar conceptos abstractos.

[19] Pedro C. Santana Mancilla, Bárbara Paola Muro Haro. Tangible Interfaces to Support the Teaching of Reading and Writing to Children with Down syndrome, IEEE Learning Technology Newsletter, Vol. 13, No. 2 (2011), 9-12.

[20] P. C. Santana, L. A. Castro, A. Preciado, V. M. González, M. D. Rodríguez and J. Favela. Preliminary Evaluation of Ubicomp in Real Working Scenarios. In the proceedings of the 2nd Workshop on Multi-User and Ubiquitous User Interfaces (MU3I) at IUI 2005 (2005). 